\title{
Application of Acceptance Sampling Techniques in Manufacturing forging Products
}

\author{
Dr. Divya.P.R \\ Assistant Professor \\ Department of Statistics \\ Vimala College, Thrissur, Kerala, India
}

\begin{abstract}
Statistical quality control (SQC) is an integral part of the paradigm of quality. Quality control emerges an important role in industrial economy. Acceptance sampling provides criteria and decision rules for determining whether to accept or reject a batch based on a sample. Acceptance sampling is useful for testing the quality of batches of items, especially when a large number of items must be processed in a short time. Acceptance sampling is used for quality assurance and in recent years, it has become typical to work with suppliers to improve the process performance. This Paper relates to a case study which describes the application of acceptance sampling in testing of forged product (CONNECTING ROD WITH CAP). This paper discusses the use of acceptance sampling technique as a practical tool for quality assurance applications to decide whether the lot is to be accepted or rejected. This study analyses, the effectiveness in the application of acceptance sampling in manufacturing forging products. The study was conducted using case study methodology at one of the manufacturing company coded name: company A. In the manufacturing environment, quality improves reliability, increases productivity and customer satisfaction. Quality in manufacturing requires the practice of quality control. The term sampling inspection plan, is used when the quality of product is evaluated by inspecting samples rather than by total inspects, which required cost and time Acceptance sampling is also applied together with SPC to get better results of process and product improvement. The case study has shown that quality control implementation in Company A, relies heavily on acceptance sampling.
\end{abstract}

Key Words- Acceptance Sampling, Forged products, Gauge Performance curve

\section{INTRODUCTION}

Acceptance sampling is one of the oldest aspects of quality assurance and used primarily for incoming and outgoing lot by lot quality assurance. Sampling is generally less expensive than hundred-percent inspection and in case of destructive testing it is the only way. It also leads to less handling of the product and therefore chances of damage to the product are significantly reduced. Besides, by resorting to sampling inspection manpower requirement for testing/inspection and amount of inspection error which are often considerably reduced. Particularly in production set-up of high- quantity, repetitive inspection such as hundred-percent inspection and exhaustion of inspector normally fails to identify all nonconformities or non-conforming units and some of the non-conforming units inadvertently pass the inspection system Sampling also plays the role of strong motivator to improve quality as entire batch or lot may be rejected. However, sampling inspection has certain disadvantages. One of the prime disadvantages is probability of acceptance lot of "bad quality" and rejection of lot of "good quality"; however, risk of committing such mistakes is known and it is based on the economy of sampling inspection versus hundredpercent inspection. Besides, less information is generated about the product quality compared to that obtained while carrying out with hundred percent inspection. Implementation of sampling plan requires more planning and documentation where as hundred-percent inspection requires none.

Depending upon the type of data, acceptance sampling can be divided into two categories; attribute and variable. The detail about both types of sampling plans is well described in the literature. In both types of sampling inspection, samples are randomly chosen from the batch, lot or process and based upon the acceptance and rejection criteria the lots are accepted or rejected. Design of a sampling plan is basically based on four factors; Acceptable Quality Level (AQL), $\alpha$ (Producer's risk), Reject Quality Level (RQL) and $\beta$ (Consumer's risk).

AQL - Lot quality that has high chances of acceptance with a particular sampling plan.

RQL - Lot quality that has low chances of acceptance with a particular sampling plan. 
$\alpha$ - The risk associated with rejecting a lot of "AQL" quality. (1- $\alpha)$ the probability of accepting lot of AQL quality

$\beta$ - is the risk of accepting a lot of "RQL" quality.

Values for these factors are arrived through mutual agreement between producer and consumer. Best sampling plan is the one that satisfies the interest of producer as well as consumer.

If one state that $\mathrm{AQL}=0.02$ and $\alpha=0.05$, it means that the lots that are $2 \%$ non-conforming (AQL) should be accepted $95 \%$ of time and rejected only $5 \%$ time. Likewise for, $\mathrm{RQL}=0.08$ and $\beta=0.10$ means that the lots that are $8 \%$ nonconforming (RQL) should be accepted only $10 \%$ of time and rejected only $90 \%$ time.

Variable sampling plan is employed where quality characteristics are measured on a numerical scale like weight, pressure, temperature etc. Advantage of variable sampling plan over attribute sampling plan is that for the same level of quality assurance it requires much smaller sample size, provides information in regards to lot quality leading to identification of areas for quality improvement. Some disadvantages of variable sampling plans are separate sampling plan required for each quality characteristics; accuracy of conclusion depends on normality for the measured data and generally requires more expensive measuring instrument.

\section{II: FORGING PRODUCT MANUFACTURING AND TESTING}

Forging refers to the process of plastically deforming metals or alloys to a specific shape with a compressive forge exerted by some external agency like hammer, press roles or by an upsetting machine of some kind. The portion of work in which the forging is done is termed as "forge'. The work is mainly performed by means of heavy hammers, forging machines and presses. Forging processes are among the most important manufacturing techniques since forged are used in small tools, rail- road equipments and aviation industries.

Forging refines the structure of metals by smashing up large grain formations and closing the cavities that are present. It also improves the mechanical properties thereby helping to withstand dynamic forces as well as static loads available. Forge (D).

The metals and alloys are classified into Good Forge (GF), Somewhat Difficult Forge (SD) and Difficult

- Aluminium alloys (GF)

- Magnesium Alloys (GF)

- Copper Alloys (GF)

- Carbon Steel Alloys (GF)

- Martensite Stainless Steels (SD)

- Nickel Alloys (SD)

- Titanium Alloys (D)

\section{MANUFACTURING OF COMPANY A:}

Company A, is a subsidiary of Steel industrials in Kerala. Company A cater to a wide range of Industries in Defense, Automobile, Heavy engineering, Aero Space Research, Railways, Earthmoving Equipments.

Main production Machinery comprise of 10 Ton and 6 Ton closed of 7500 Metric Tons of Carbon and Alloy Steel, non- ferrous, Special metals viz. Titanium and Nickel Based alloys, stainless Steel etc. The supporting machinery consists of Billet Shearing machines, 1000 Ton and 6500 Ton trimming presses, Electric and oil fired furnaces for heat treatment and billet heating, shot blasting machines etc. There is a modern heat treatment plant equipped with number of furnaces both LDO fired and electrically heated and a charging machine which takes care of loading and unloading of heat treatment charges

\section{II(a): TESTING AND INSPECTION FACILITIES}

Surface conditioning is done by shot blasting / grinding and final inspection is carried out once again to ensure quality requirements. Stage-wise inspection non- conformities are taken care through timely corrective and preventive action. The company has set up a system of total quality control consisting of an array with state- of -art specialty equipments where their products go through a series of rigorous tests, destructive test including tensile, 
jominy and impact testing, wet analysis, carbon- Sulphur determination, metallographic and non- destructive tests using Spectrometer, Microscope, Ultrasonic flaw detection, Magnaflux crack detection, Die Penetrant etc, tests that ensures quality. Setting and control of quality standards at all stages right from the receipt of raw material to the finished product through quality plan makes them deliver superior quality forging with close dimensional tolerances and metallurgical properties. Here the product CONNECTING ROD WITH CAP and its weight measure are considered.

The assumption underlined is that the end test value is same at any point of the sample forging product. Acceptability of this assumption is mostly depends upon variation of the parameter along with weight measure of the forged product or in statistical terms process variation for the parameters and GRR (Gauge Repeatability and Reproducibility) performance of the measuring instruments. Variation is controlled to a minimum level so as to avoid any parameter going out of specification limit at any point of the tested sample. As forging product testing generates numerical data, for quality assurance of the parameters, variable sampling plan is most appropriate.

\section{III: CUSTOMIZATION OF SAMPLING PLAN}

A sampling plan customized to high volume forging product quality testing has been designed to overcome the hurdles with conventional variable sampling plan. Two variations- process and measurement are considered to design such sampling plan.

\section{III(a): PROCESS VARIATION}

Measurement of weight and hardness parameters of the forging product CONNECTING ROD WITH CAP is destructive in nature. Here top or bottom measured values are assumed to be same at any point of the product. Graphical methods are also useful when one is selecting probability distribution to describe a population. Probability Plotting is a graphical method for determining whether sample data conform to a hypothesized distribution based on a subjective visual examination of the data. The measurements of the sample are analyzed for the normality using "Normal Probability Plot". If the measurements of sample appear as straight line on normal probability plot, then the mean of the sample is used for assigning values for the spools of entire batch. An example is given below for weight measure to the forged product CONNECTING ROD WITH CAP.

Table3.1 shows base data of Weight measure for the forged product CONNECTING ROD WITH CAP. Fig.3.1 shows result of normality test of base data.

\begin{tabular}{|c|c|c|c|}
\hline Table 3.1: Base data of Weight measure (D) \\
\begin{tabular}{|c|c|c|} 
Weight \\
Obseasure(D)
\end{tabular} & Observations & $\begin{array}{c}\text { Weight } \\
\text { Measure(D) }\end{array}$ \\
\hline 1 & 27.4 & 21 & 27.6 \\
\hline 2 & 27.5 & 22 & 27.0 \\
\hline 3 & 27.7 & 23 & 27.2 \\
\hline 4 & 27.6 & 24 & 27.0 \\
\hline 5 & 27.6 & 25 & 27.1 \\
\hline 6 & 27.6 & 26 & 26.9 \\
\hline 7 & 27.3 & 27 & 27.1 \\
\hline 8 & 27.5 & 28 & 27.1 \\
\hline 9 & 27.0 & 29 & 26.8 \\
\hline 10 & 26.9 & 30 & 26.8 \\
\hline 11 & 27.0 & 31 & 26.9 \\
\hline 12 & 27.1 & 32 & 27.3 \\
\hline 13 & 27.5 & 33 & 26.9 \\
\hline 14 & 27.0 & 34 & 27.7 \\
\hline 15 & 27.1 & 35 & 27.5 \\
\hline 16 & 27.0 & 36 & 27.6 \\
\hline 17 & 27.3 & 37 & 27.5 \\
\hline 18 & 27.0 & 38 & 27.2 \\
\hline 19 & 27.1 & 39 & 27.2 \\
\hline 20 & 27.0 & 40 & 27.7 \\
\hline
\end{tabular}


In assessing the "closeness" of the points to the straight line, imagine a "fat pencil" lying along the line. If all the points are covered by this imaginary pencil, then a normal distribution adequately describes the data. Since the points in Figure1 would pass the "fat pencil" test, one can conclude that the normal distribution is an appropriate model. The measurements of sample appear as straight line on normal probability plot. Therefore the mean of the sample is used for assigning the values for the spools of the entire batch.

Figure 3.1: Normal Probability Plot of base data

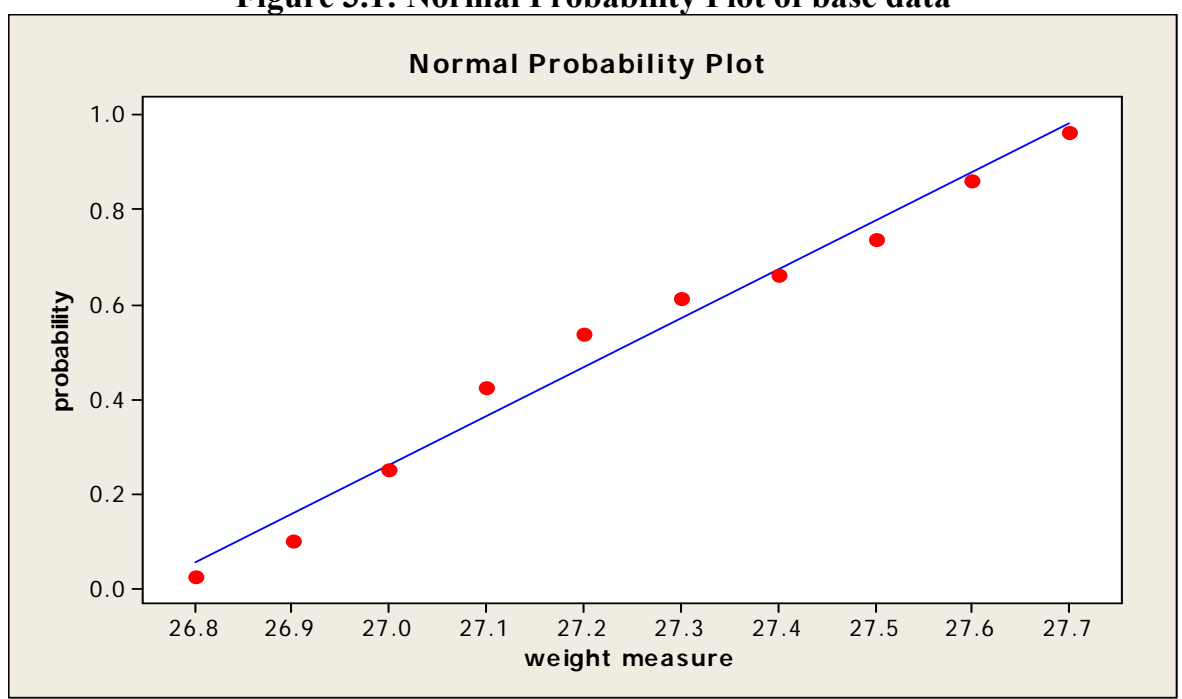

Average $=27.233$, Standard Deviation $=0.28137, \quad \mathrm{~N}=40$

III(b): MEASUREMENT VARIATION (GAUGE PERFORMANCE CURVE)

Gauge performance curves are determined for each parameter and measurement system from gauge repeatability and reproducibility (GRR) study. GRR study is carried with five samples covering entire specification range, three operators, and three readings per sample per operator. Fig.3.2 is Gauge Performance curve of Weight measure having upper and lower specification limit $20 \mathrm{D}$ and 30D respectively. The $99 \%$ zone for the measuring system is 20.4 to 29.6 D. It means that if the actual measurement of Weight parameter is between 20.4 and 29.6 then probability of making correct decision $99 \%$ of time. The frequency of measurement system analysis is normally six month until and unless there is breakdown or major maintenance work.

Figure 3.2: Gauge Performance curve for Weight Measure

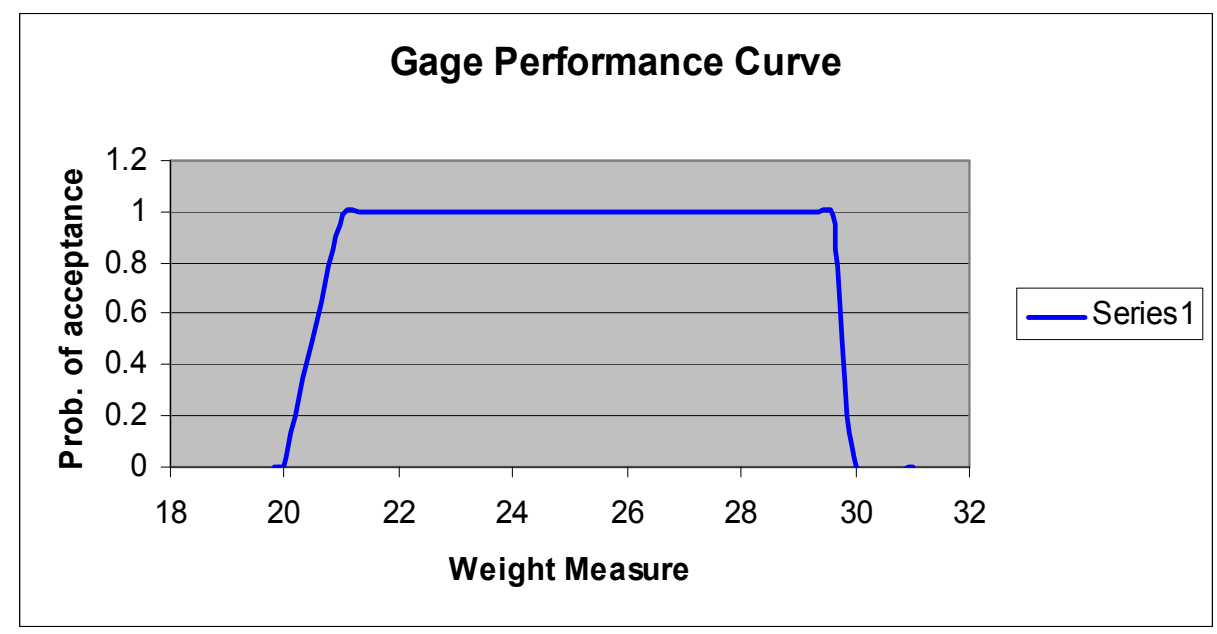

III ( c ): BENEFITS 
are:

Benefits accrued by introducing customized sampling plan for high volume production of forged product

- No extra holding time is required for customized sampling plan.

- Insignificant difference between reported and actual values for un-tested samples.

- As measurement variation is considered during designing of sampling plan, there is much less possibility of passing failed forging because of sampling particularly for the batches where population is close to the extreme limit of specification range.

- With variable sampling plan, 70-80\% less samples are required to test and one set of weight measure testing instrument can do testing same volume of production for which four sets of instruments would be required when $100 \%$ testing in place.

- $\quad$ Other benefits of sampling like less manpower, power, and handling damages are accomplished.

\section{IV: CONCLUSION}

Effective acceptance sampling involves effective selection and the application of specific rules for lot inspection. The acceptance- sampling plan applied on a lot-by-lot basis becomes an element in the overall approach to maximize quality at minimum cost. Since different sampling plans may be statistically valid at different times during the life of a process, therefore all the sampling plans should be periodically reviewed. From the case study, it was found that the company has clear vision of their strengths, weaknesses, opportunities and threats analysis. A customized variable sampling plan is designed for high volume forging product quality testing to overcome various implementation issues like high holding time for batch-wise testing, passing of forging product and high difference between actual and reported values. The customized sampling is found in good agreement with conventional sampling. The continuous improvement and review of acceptance sampling plan is important to improve the products quality and ensure continuous customer satisfaction.

\section{REFERENCES}

[1] AMERICAN NATIONAL STANDARDS Institute/American Society for Quality Control (ANSI / ASQC) Standard A2, "Terms, Symbols and Definition for Acceptance Sampling”, American Society for Quality Control, Milwaukee, Wilconsion. USA,1987

[2] BURGESS, A.R. , "A Graphical Method of Determining a Single Sampling Plan”, Industrial Quality Control, Vol. 4, No.6, pp. 2527,1948

[3] CAMERON, J.M, “Tables for constructing and for computing the operating characteristics of single sampling plans”, Industrial Quality Control, Vol.9, No.1, pp.37-39,1952

[4] MONTGOMERY. DOUGLAS. C , "Introduction to Statistical Quality Control", John. Wiley and sons, Inc, 1985

[5] PEACH. P, "An Introduction to Industrial Statistics and Quality Control", 2nd Edition, Edwards and Broughton Raleigh, North Carolina, 1947

[6] SCHILLING, E.G, “Acceptance Sampling in Quality Control”, Marcel Dekker, Inc., New York,1982

[7] SUDIPTA BHAUMIK and KULDEEP BHARGAVA, "Application of acceptance sampling in testing of optical fiber", Proceedings of International Conference on Optics and Optoelectronics, 12-15 Dec. 2005, IRDE, Dehradum, INDIA,2005.

[8] SURESH, K.K, “A Study on Acceptance Sampling using Acceptable and Limiting quality Levels”, Ph.D Thesis, Bharathiar University, Tamilnadu,1993 